\title{
Profilin and Rop GTPases are localized at infection sites of plant cells
}

\author{
Short communication
}

\author{
I. Schütz ${ }^{* *}$, S. Gus-Mayer ${ }^{+}$, and E. Schmelzer* \\ Central Microscopy, Max Planck Institute for Plant Breeding Research, Cologne
}

Received May 25, 2005; accepted September 8, 2005; published online May 30, 2006

(c) Springer-Verlag 2006

\begin{abstract}
Summary. We have found 5 profilin cDNAs in cultured parsley cells, representing a small gene family of about 5 members in parsley. Specific antibodies were produced using heterologously expressed parsley profilin as antigen. Western blot analysis revealed the occurrence of similar amounts of profilin in roots and green parts of parsley plants. Immunocytochemical staining of parsley cells infected with the oomycetous plant pathogen Phytophthora infestans clearly revealed that profilin accumulates at the site on the plasma membrane subtending the oomycetous appressorium, where the actin cables focus. We also observed the accumulation of Rop GTPases around this site, which might point to a potential function in signaling to the cytoskeleton.
\end{abstract}

Keywords: Fungal infection; Plant defense; Cell polarization; Actin filament reorganization.

\section{Introduction}

In plants, the actin cytoskeleton performs essential tasks in many cellular processes, including morphogenesis, cell division, and cytoplasmic streaming (Volkmann and Baluska 1999, Mathur and Hülskamp 2002). Since plant cells are immotile and encased by a rigid cell wall, dynamic actin filament organization appears to be very important for the targeted transportation of organelles and vesicles, and the site-specific delivery of materials.

The remodeling of actin filament architecture is known to be regulated by associated proteins that bind either to monomeric or polymeric actin. One of the best character-

\footnotetext{
* Correspondence and reprints: Zentrale Mikroskopie, Max-PlanckInstitut für Züchtungsforschung, Carl-von-Linné-Weg 10, 50829 Köln, Federal Republic of Germany.

E-mail: schmelze@mpiz-koeln.mpg.de

** Present address: Halle, Federal Republic of Germany.

${ }^{+}$Present address: Geretsried, Federal Republic of Germany.
}

ized examples of such proteins in plants is profilin (Staiger et al. 1997). This abundant, low-molecular-mass $(12-15 \mathrm{kDa})$ cytoplasmic protein has been identified in all eukaryotic organisms studied. Several isoforms have been found, also in plants, that appear to be differentially expressed and are encoded by small multigene families (Kandasamy et al. 2002). Profilin was originally characterized by its ability to bind in a $1: 1$ complex to monomeric actin (Carlsson et al. 1977, Sun et al. 1995). However, its role in regulating the organization of the actin cytoskeleton is rather complex and not yet fully understood. It can either promote or prevent actin polymerization depending on the size of the globular-actin (G-actin) pool and the ratio of this pool to profilin, as well as the differential cooperation with a number of other actin-binding proteins, for instance, actin-depolymerizing factor, $\beta$-thymosin and formin homology proteins (Ballweber et al. 1998). Profilins also interact with other ligands in addition to actin: membrane polyphosphoinositides and stretches of poly- or oligoL-proline in proline-rich proteins (Drobak et al. 2004). These properties, particularly the binding to phosphatidylinositol 4,5-bisphosphate $\left(\mathrm{PIP}_{2}\right)$ resulting in dissociation of profilactin, hint at a role for profilin in signal transduction; indications for this have been found in animal and fungal organisms (Schlüter et al. 1998). From all these data, one might expect profilin to be concentrated at sites of highly dynamic actin filaments.

Animal and fungal GTPases of the Rho family, comprising $\mathrm{Cdc} 42$, Rac and Rho subfamilies, are well known for their role as key regulators of the actin cytoskeleton (Hall 1998). Besides mediating alterations in actin dynamics 
and intracellular transport, they control, via activation of protein kinase cascades, a broad range of physiological changes, including gene transcription, cell cycle progression and production of reactive oxygen species (Ridley 2001). Recent data imply that plant Rho homologues may have similar cellular functions (Valster et al. 2000, Zheng and Yang 2000, Vernoud et al. 2003). Pollen tubes elongate by tip growth, which is dependent on actin-filament-mediated transport of secretory vesicles along the longitudinal axis to the tip. Genetic evidence clearly shows that Ractype proteins have an essential function in polar growth and act by controlling actin filament assembly (Kost et al. 1999). Furthermore, pollen tube Rac localizes to the plasma membrane at the tip, where it physically associates with a phosphatidylinositol monophosphate kinase activity and colocalizes with $\mathrm{PIP}_{2}$, the specific product of this enzyme reaction. Similarly, polar localization of Rop (Rac of plants) GTPases was also found in Arabidopsis thaliana root hair trichoblasts at sites of outgrowing root hairs, even before budding (Molendijk et al. 2001), indicating involvement in polar cytoskeletal reorganization. These data suggest that small GTPases act by regulating site-directed actin filament polymerization. This view was recently reinforced by the finding that ROPs activate two counteracting pathways controlled by the ROP targets RIC3 and RIC4 (Fu et al. 2005, Gu et al. 2005). These pathways regulate each other to control actin dynamics and cell morphogenesis, for example, tip growth in pollen tubes and interdigitating growth in pavement cells of the leaf epidermis. Furthermore, small GTPases may function as molecular switches mediating between membrane-receptor-based perception of exogenous signals and their transduction to the cytoskeleton in cooperation with the polyphosphate inositol pathway and $\mathrm{PIP}_{2}$-actin-binding proteins, such as profilin and actin-depolymerizing factor.

An excellent example of exogenously triggered induction of cytoskeleton polarization is the plant cell defense response to fungal infection. An important component of plant resistance to fungal pathogens is the formation of localized wall thickenings at penetration sites, so-called papilla, to prevent pathogen ingress (Schmelzer 2002). This process comprises site-directed transport and secretion of various materials which are deposited at the plant cell wall beneath and around the fungal infection structures and involves reorientation of the actin filament and microtubule architecture towards the penetration site (Schmelzer 2002, Takemoto et al. 2003). We have made intensive use of cultured parsley cells infected with Phytophthora infestans as a model system to study the plant defense response at the level of individual cells
(Gross et al. 1993, Naton et al. 1996). Microscopic examination revealed that major features of the defense response in this model system largely resemble the in planta situation, including cytoplasmic and cytoskeletal reorganization. Here we have studied the occurrence and expression of profilins in parsley and the accumulation of profilin and Rop GTPases together with the formation of a new actin focus at the penetration site.

\section{Material and methods}

\section{Cultivation of plant cells and oomycetes}

Suspension-cultured Petroselinum crispum cells were grown in HA medium in constant darkness at $26^{\circ} \mathrm{C}$ as described earlier (Kombrink and Hahlbrock 1986). Phytophthora infestans mycelium was grown on vegetable juice agar at $18{ }^{\circ} \mathrm{C}$ in the dark. Production of sporangia and maturation and release of zoospores on rye agar was performed according to the procedure described by Gross et al. (1993).

\section{Cloning of parsley (P. crispum) profilins}

Degenerate primers were derived from two profilin regions conserved among plants (Christensen et al. 1996): primer 1, AAR TAY ATG GTI ATI CAR GGI GA (amino acid sequence KYMVIQGE); primer 2 (reverse), TCI ACI ACC ATR TTR CAY TGI CC (amino acid sequence GQCNMVVE). By using these primers for PCR with cDNA from cultured parsley cells as template, a respective profilin fragment was amplified. The missing $3^{\prime}$ and $5^{\prime}$ ends were completed by rapid amplification of cDNA ends. The resulting clone was named PcPRF1. The sequence was used to screen the cDNA library of cultured parsley cells for other profilin-like sequences. In total, 30 profilin-like sequences were found corresponding to 5 different profilin cDNAs named PcPRF1 to PCPRF5.

\section{DNA sequencing}

Sequencing was performed by the in-house DNA sequencing facility on Applied Biosystems (Weiterstadt, Federal Republic of Germany) Abi Prism 377 and 3700 sequencers using BigDye-terminator chemistry. Premixed reagents were from Applied Biosystems.

\section{Generation and purification of antibodies}

PcPRF1 was cloned into the pQE31 vector via BamHI/PstI and transformed into Escherichia coli to generate PcPRF1-6 $\times$ His. Expression and purification of the fusion protein was performed as described by Robatzek and Somssich (2001). Briefly, heterologous expression was induced by addition of IPTG to a $500 \mathrm{ml}$ liquid culture of E. coli during exponential growth. At an $\mathrm{OD}_{600}$ of 2.0, cells were harvested by centrifugation and lysed. PcPRF1- $6 \times$ His was purified from the lysate using Ni-agarose affinity chromatography. The eluates from the $\mathrm{Ni}$ agarose column were checked for purity by sodium dodecyl sulfatepolyacrylamide gel electrophoresis (SDS-PAGE). Protein bands were cut out from the polyacrylamide gels, frozen in liquid nitrogen and ground with a mortar and pestle to a fine powder. Immunization and generation of antisera in rabbits was performed by Biogenes Inc., Berlin, Federal Republic of Germany. Antisera were tested with protein extracts from parsley. The antiserum was affinity-purified using heterologously expressed PcPRF1 bound to Ni-agarose following the protocol of Gu et al. (1994). 


\section{Western blot analysis}

Parsley organs and tissues and suspension-cultured parsley cells were ground in liquid nitrogen using a mortar and pestle. The powder was resuspended in extraction buffer (sterile solution of $50 \mathrm{mM}$ Tris- $\mathrm{HCl}$, pH 8.0, containing $150 \mathrm{mM} \mathrm{NaCl}, 10 \mathrm{mM}$ EDTA, $0.1 \%$ SDS; just before use, $20 \mu \mathrm{l}$ of $200 \mathrm{mM}$ permethylene sulfoxide [PMSF] in acetone and $100 \mu \mathrm{l}$ of $20 \%$ Triton-X 100 were added to $10 \mathrm{ml}$ of this buffer). Cell debris was removed by centrifugation at $10000 \mathrm{~g}$ for $30 \mathrm{~min}$ at $4{ }^{\circ} \mathrm{C}$. Aliquots of the supernatant or microsomal preparations were separated by PAGE (10-15\%) along with prestained molecular-weight markers (SeeBlue; Invitrogen, Karlsruhe, Federal Republic of Germany). For microsomal preparations, the tissue was ground at $4{ }^{\circ} \mathrm{C}$ with sand in $50 \mathrm{mM}$ HEPES, pH 5, containing $0.5 \mathrm{M}$ sucrose, $6 \mathrm{mg}$ of polyvinyl polypyrrolidine per $\mathrm{ml}, 5 \mathrm{mM}$ ascorbic acid, and $1 \mathrm{mM}$ dithiothreitol. The homogenate was centrifuged at $7000 \mathrm{~g}$. The supernatant was centrifuged at $32000 \mathrm{~g}$ and $4{ }^{\circ} \mathrm{C}$, and the resulting pellet was resuspended in $1 \mathrm{ml}$ of $5 \mathrm{mM} \mathrm{K} \mathrm{H}_{2}-\mathrm{H}_{2} \mathrm{PO}_{4}$ buffer, $\mathrm{pH} 7.8$, containing $0.33 \mathrm{M}$ sucrose, and stored at $-20{ }^{\circ} \mathrm{C}$. Protein bands were transferred to nitrocellulose membrane by electrophoretic blotting (Electro Eluter; Bio-Rad, Munich, Federal Republic of Germany). Membranes were blocked with 2\% (w/v) milk powder (Neuform, Hamburg, Federal Republic of Germany) in TBS $(8 \% \mathrm{NaCl}, 0.2 \% \mathrm{KCl}, 3 \%$ Tris- $\mathrm{HCl}, \mathrm{pH} 7.4)$ for $60 \mathrm{~min}$ at room temperature and then incubated overnight at $4{ }^{\circ} \mathrm{C}$ with appropriate concentrations of primary antibodies $(1: 500$ to $1: 2000)$. After rinsing 3 times in milk powder-TBS, secondary antibodies labeled with alkaline phosphatase (Sigma-Aldrich, Munich, Federal Republic of Germany) were added ( $1: 1000$ dilution) and membranes were incubated for $2 \mathrm{~h}$ at room temperature. After rinsing 3 times with TBS-T (phosphate-buffered saline [PBS] with $0.1 \%$ Tween 20 ) and TBS, and once with water, the blots were stained with 5-bromo-4-chloro-3-indolylphosphate toluidine salt-nitro-blue tetrazolium chloride (Sigma-Aldrich) following the manufacturer's instructions. After the appearance of bands, the reaction was stopped by the addition of deionised water.

\section{Immunocytochemistry}

Cultured parsley cells were infected with $P$. infestans on microscope slides and subsequently immunocytochemically stained according to the method of Gross et al. (1993). Affinity-purified anti-profilin antibodies and affinity-purified antibodies against Rop4 from Arabidopsis thaliana were used as primary antibodies (dilutions of $1: 10$ to $1: 100$ in bovine serum albumin-PBS). In competition experiments, $1-10 \mu \mathrm{g}$ of purified, heterologously expressed PcPRF1- $6 \times$ His was added to the primary anti-profilin antibodies. The anti-Rop4 antibodies were kindly provided by A. Molendijk. Secondary antibodies were diluted $1: 200$ in bovine serum albumin-PBS for CY3-conjugated antibodies and 1: 150 for fluorescein isothiocyanate-conjugated anti-rabbit immunoglobulin $G$ antibodies (Sigma-Aldrich). Slides were incubated with the antibody solution for $1 \mathrm{~h}$ at $37^{\circ} \mathrm{C}$ and then rinsed 3 times with PBS and 3 times with microtubule-stabilizing buffer. The stained cells were inspected and photographed with a Zeiss Axiophot light microscope equipped with epifluorescence and a digital imaging system (JVC KY-F70 camera, Diskus imaging software; Technisches Büro Hilgers, Königswinter, Federal Republic of Germany).

\section{Results \\ Characterization and expression of profilins from P. crispum}

Using PCR technology with P. crispum cDNA as template and degenerate primers, a cDNA fragment of profilin was amplified. The fragment was subjected to rapid amplification of cDNA ends and a full-length cDNA, PcPRF1, was obtained.

Using this cDNA as a probe to screen a cDNA library of suspension-cultured P. crispum cells, four additional profilin cDNAs with very similar deduced amino acid sequences (GenBank accession nr. AY900012-AY900016) were found. Employing DNA from cultured parsley cells in Southern blot experiments with PcPRF1 as the probe, 3 to 5 major bands were detected under moderate stringency. Thus, the parsley profilins constitute a small gene family of about 5 members.

Specific antibodies were generated against heterologously expressed PcPRF1 and affinity purified. These antibodies recognized purified, heterologously expressed PcPRF1 on Western blots (Fig. 1, lane 2) and a band corresponding to the molecular mass of profilin, about $14 \mathrm{kDa}$, was detected by Western blot analysis of extracts from cultured parsley cells, as well as from leaves and roots of parsley plants (Fig. 1, lanes 3-5). The preimmune serum control displayed no signals (Fig. 1, lane 1). The parsley profilin isoforms show high homology among themselves (87-98\%) and with the profilins from Arabidopsis thaliana (85-91\%). There is also considerable homology (44-48\%) with the mouse and human profilins. Thus, the antibodies against PcPRF1 most probably do not discriminate between isoforms. Irrespective of isoforms, profilins were found to be expressed at similar levels in terrestrial and aerial parts of parsley plants. Considerably higher levels were found in maturing pollen by immunohistochemical staining of flower bud sections (data not shown).

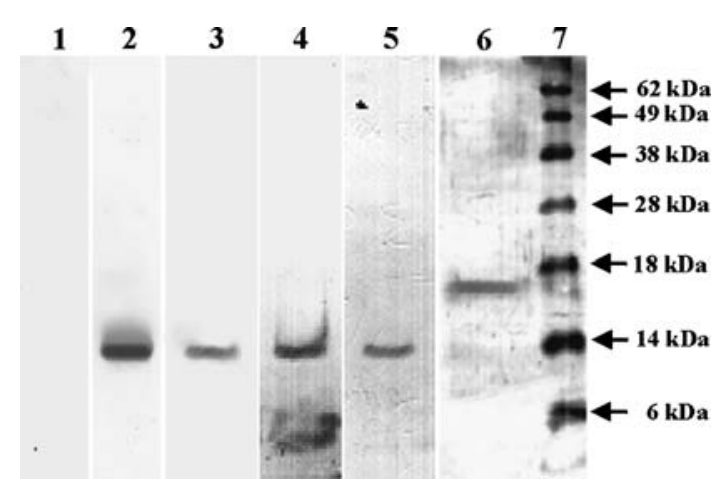

Fig. 1. Western blot analysis using preimmune serum and anti-profilin and anti-Rop-GTPase antibodies. Protein extracts from cultured parsley cells were incubated with preimmune serum (1), purified recombinant profilin (2), and protein extracts from cultured parsley cells (3), parsley leaves (4), and roots (5) were incubated with the anti-profilin antibodies, and a microsomal preparation from cultured parsley cells was incubated with the anti-Rop4 (A. thaliana) antibodies (6). Prestained protein markers for the indicated molecular masses were coseparated and blotted (7) 
Cellular redistribution of actin, profilin, and Rop-GTPase upon pathogen infection

Cultured parsley cells were infected with the oomycetous plant pathogen $P$. infestans to study the induced changes in cellular organization of the actin cytoskeleton and its binding protein profilin, as well as the potential signaling component Rop GTPase, by immunocytochemistry. During cocultivation of $P$. infestans germlings and cultured parsley cells on microscopic slides, the growing germ tube of the pathogen contacts and attaches to cells through the formation of an appressorium and subsequently penetrates the cell wall. Upon attachment and penetration, the plant cell reorients actin filaments towards the area of the plasma membrane beneath the appressorium of the pathogen (Fig. 2A, B). As seen in Fig. 2C and D, strong accumulation of profilin was found both at the infection site and in the plant cell nucleus. To verify the specificity of the immunocytochemical staining and the redistribution of profilin, we performed a number of control experiments (Fig. 3). When infected cultured parsley cells were incubated with $\mathrm{Cy} 3$ fluorescently labeled secondary antibodies alone, no fluorescence was detectable (Fig. 3A, B) and only weak, unspecific fluorescent labeling was observed after staining with the preimmune serum (Fig. 3E, F). The strong staining of nuclei was also seen in uninfected cells incubated with the anti-profilin antibodies (Fig. 3C, D). Addition of purified, heterologously expressed PcPRF1 to the infected cells drastically decreased the immunostaining at the infection site and of the nucleus by competing with the cellular profilin for the antibody (Fig. 3G, H). Thus, the accumulation of profilin at the infection site appeared to be specific and correlated with the reorientation of actin filaments towards this site.
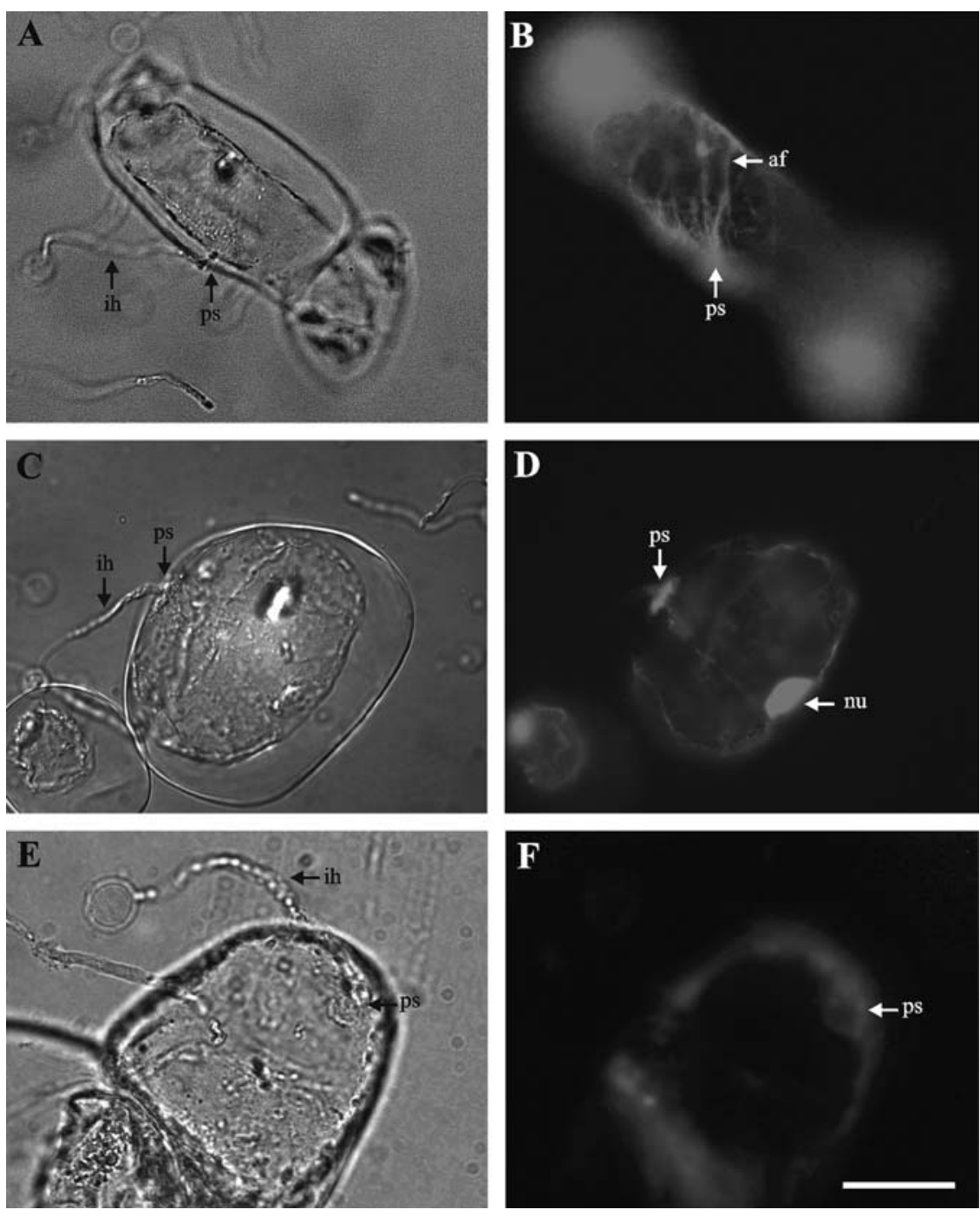

Fig. 2 A-F. Immunocytological localization of actin, profilin, and Rop GTPase in infected cultured parsley cells. Cultured parsley cells were infected with $P$. infestans on microscope slides and then immunocytochemically stained with primary antibodies specific for actin (A and $\mathbf{B})$, profilin $(\mathbf{C}$ and D) and A. thaliana Rop4 (E and $\mathbf{F})$, and Cy3 fluorescently labeled secondary antibodies. Panels A, C, and E are bright-field images of the respective fluorescence images $\mathrm{B}, \mathrm{D}$, and F. af Actin filament; ih infection hypha; $n u$ nucleus; $p s$ penetration site. Bar: $20 \mu \mathrm{m}$ 

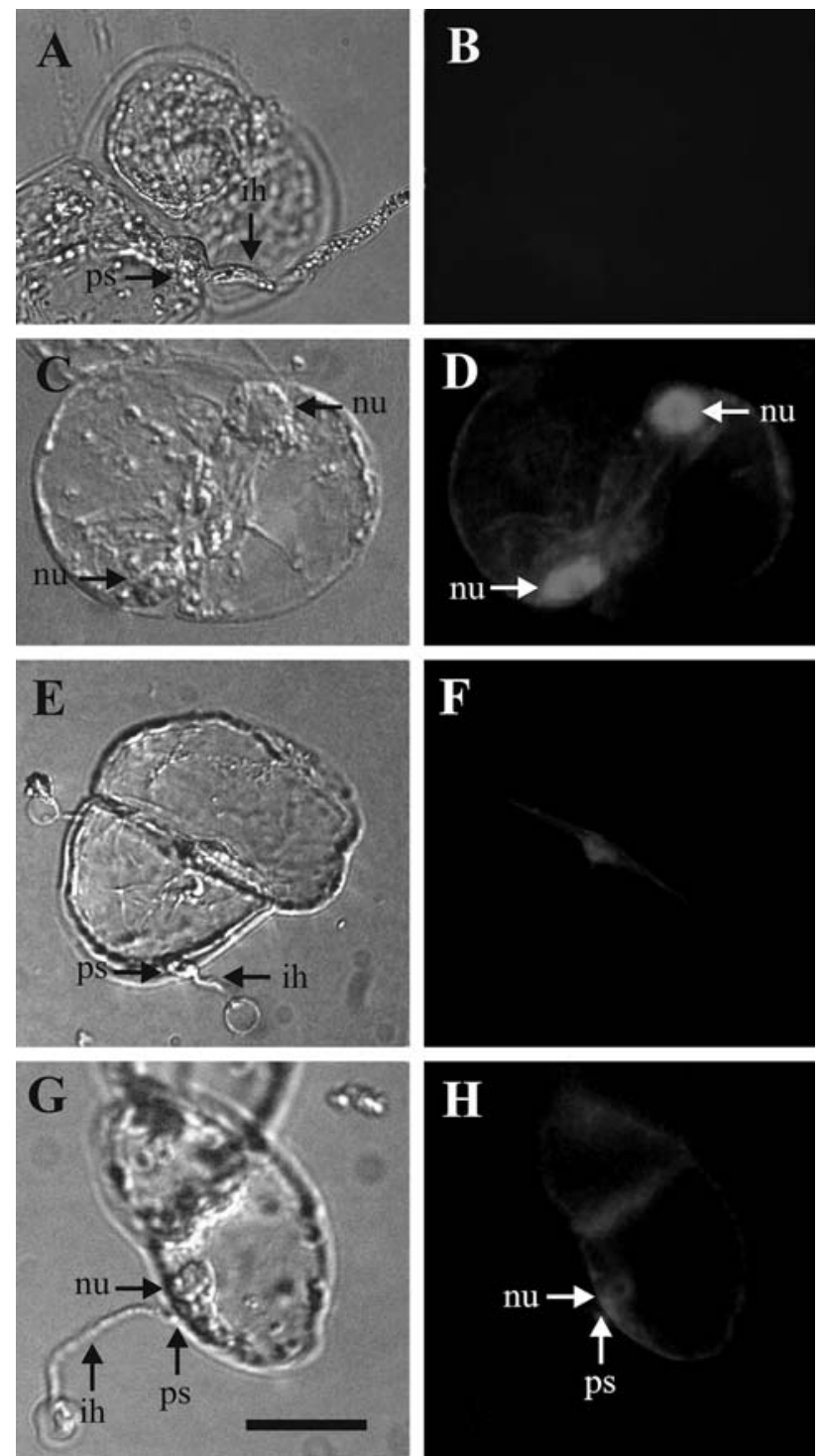

Fig. 3 A-H. Immunocytochemical control experiments with cultured parsley cells. A and B Infected cells incubated with secondary Cy3 fluorescently labeled antibodies only; $\mathbf{C}$ and $\mathbf{D}$ noninfected cells stained with anti-profilin antibodies and Cy3 fluorescently labeled secondary antibodies; $\mathbf{E}$ and $\mathbf{F}$ infected cells stained with preimmune serum and $\mathrm{Cy} 3$ fluorescently labeled secondary antibodies; $\mathbf{G}$ and $\mathbf{H}$ infected cells stained with anti-profilin antibodies in the presence of $10 \mu \mathrm{g}$ of purified recombinant profilin and $\mathrm{Cy} 3$ fluorescently labeled secondary antibodies. Panels A, C, E, and G are bright-field images of the respective fluorescence images B, D, F, and H. ih Infection hypha; nu nucleus; ps penetration site. Bar: $20 \mu \mathrm{m}$

The potential involvement of small GTPases in the defense mechanism was investigated using antibodies against Rop4 from A. thaliana. First, the cross-reactivity of these antibodies with parsley proteins was tested in Western blots. In protein extracts of parsley microsomal fractions, one single band at a molecular mass of about $18 \mathrm{kDa}$, corresponding to the molecular mass of monomeric Rop, was detected (Fig. 1). Immunocytochemical staining of infected parsley cells with the anti-Rop4 antibodies showed weak but significant staining at the plasma membrane, especially at the infection site, where a halo of antibody fluorescence was observed around the invading hyphae (Fig. 2E, F).

\section{Discussion}

Profilins have been found in all eukaryotic organisms and appear to be ubiquitously expressed, indicating essential functions. In plants, profilins are encoded by small gene families of about 5 members (Staiger et al. 1993, Mittermann et al. 1995, Huang et al. 1996). Similarly, our screening of a cDNA library and Southern blot analysis indicated the presence of up to 5 profilin genes in parsley. We found profilins throughout the whole plant with increased concentrations in maturing pollen of flowers, which is also typical for other plants (Christensen et al. 1996). Plant profilins were first identified as the major allergen in pollen (Valenta et al. 1991).

With respect to intracellular localization in plants, profilins are normally equally distributed within the cytoplasm, but they are often also found within the nucleus (Braun et al. 1999, Holzinger et al. 2000, Valster et al. 2003). When we overexpressed profilin (PcPRF1) as a GFP-fusion protein (C-terminal or N-terminal) in parsley protoplasts, the cytoplasm and nucleus displayed intense GFP fluorescence; however, cytoplasmic strands could no longer be observed. Coexpression of profilin-RFP and talin-GFP for fluorescent tagging of actin filaments showed the lack of transversal actin filaments and cytoplasmic strands in protoplasts (data not shown). These results confirm earlier reports that microinjection of profilin into plant cells results in the disappearance of cytoplasmic strands and transversal actin filament bundles (Staiger et al. 1994, Valster et al. 1997). Thus, the artificial elevation of the apparent cytoplasmic concentration of profilin clearly leads to the depolymerization of actin filaments and drastic disturbance of cytoplasmic morphology and dynamics, as a consequence of its sequestering function. The function of nuclear profilin is unknown, although it has been speculated that it might be involved in signal transduction cascades between the nucleus and cytoplasm (Baluska et al. 2001). Our results show that, upon fungal or oomycete infection and the consequent induction of actin filament polarization, profilin localizes to the actin focus at the plasma membrane beneath the site of cell wall penetration. In quite a number of publications, similar concentrations of profilin were found in cytoplasmic areas with high actin filament dynamics, such as the cell cortex, filopodia and focal adhesions in Acanthamoeba castellani, 
Schizosaccharomyces pombe, and mammalian cells (reviewed in Schlüter et al. 1998). In plants, profilin is codistributed with the apical actin cap in growing root hairs and is specifically localized in the bulge during root hair initiation and subsequently forms a weak tip-to-base gradient in the elongating root hairs (Baluska et al. 2000). However, in another tip-growing plant cell, the pollen tube, profilin was found to be rather homogeneously distributed and not concentrated at the tip (Vidali and Hepler 1997), and no specific localization of profilin was found in the phragmoplast of dividing plant cells, which contains a dense array of actin filaments (Valster et al. 2003). Similarly, in other studies employing microinjection of fluorescently labeled profilin into Acanthamoeba castellanii and mammalian tissue culture cells, profilin was not found to colocalize with actin filaments (Tarachandani and Wang 1996, Kaiser et al. 1999). The source of these conflicting results is presently unclear. From our control experiments, in which only secondary antibodies or preimmune serum were applied, we can rule out that the fluorescence labeling at the penetration site is simply caused by autofluorescence of cytoplasmic aggregates or unspecific antibody staining. In an earlier publication, we showed that cultured parsley cells exhibit a bright blue autofluorescence at infection sites upon UV-light excitation (330-390 nm), while other excitation wavelengths, for instance, the green light used here for Cy3 excitation, have no effect (Naton et al. 1996). The staining of nuclei in noninfected cells with the anti-profilin antibodies indicates a constitutive localization of profilin in this organelle. As we were able to substantially reduce the staining at the penetration site and in the nucleus by adding purified, heterologously expressed profilin to the anti-profilin antibodies, the labeling at these sites must be regarded as true accumulation of profilin.

In outgrowing root hair bulges, elevated levels of $\mathrm{PIP}_{2}$, a potential ligand of profilin, were found using specific anti$\mathrm{PIP}_{2}$ antibodies for immunocytochemical localization (Braun et al. 1999). In experiments with similar commercially available antibodies, we observed staining of nuclei in parsley cells but not around the penetration site (data not shown). However, it was unclear whether this was due to experimental differences, such as the fixation conditions for optimal membrane preservation. Nuclear localization of $\mathrm{PIP}_{2}$ has been clearly shown for mammalian cells (Martelli et al. 1995, Boronenkov et al. 1998, Osborne et al. 2001). The process of root hair initiation shows striking similarities in various aspects to fungal-infection-induced cellular reorganization (Schmelzer 2002). As in the cellular defense response to fungal invasion, the cell creates a special microcompartment at the cell wall, which involves site-directed reorienta- tion of actin filaments and microfilament-dependent transport processes for cell wall construction and fortification. These similarities suggest that various exogenous or endogenous triggers might induce a similar program leading to cellular polarization. Our observations of Rop GTPases accumulating around the penetration site, i.e., the site of polarization, as in the process of root hair initiation (Molendijk et al. 2001), are in line with this assumption. The activity of Rop GTPases in plant cell polarization could probably be linked to actin cytoskeleton reorganization; however, this has yet to be proven. It is already clear that small GTPases play a crucial role in plant defense responses, such as the generation of reactive oxygen species (oxidative burst), expression of defense-related genes, and production of phytoalexins (Ono et al. 2001, Wong et al. 2004). In a recent study of the defense response of barley to the biotrophic powdery mildew fungus Blumeria graminis f. sp. hordei, it was shown that actin cytoskeleton polarization to sites of attempted fungal penetration is modulated by the receptor-like transmembrane protein MLO and the RAC/ROP family G protein RACB (Opalski et al. 2005). Interestingly, in susceptible interactions of barley and B. graminis f. sp. hordei, members of the ROP G protein family were found to be important for pathogen access and, hence, establishment of disease (Schultheiss et al. 2003). Apparently, in cases of nonrecognition and impaired defense, pathogenic fungi take advantage of GTPase functions for the establishment of biotrophy. Thus, components of the signaling pathway to the actin cytoskeleton might be involved in a complex network concerned with the sensing of exogenous triggers and resulting in a variety of potential physiological answers and dynamic morphological changes.

\section{Acknowledgments}

We are very grateful to Arthur Molendijk for providing the antibodies against Rop4 from Arabidopsis thaliana. We thank Ila Rouhara and Hans-Ulrich Martin for skilful technical assistance.

\section{References}

Ballweber E, Giehl K, Hannappel E, Huff T, Jockusch BM, Mannherz HG (1998) Plant profilin induces actin polymerization from actin: $\beta$ thymosin complexes and competes directly with $\beta$-thymosins and with negative co-operativity with DNase I for binding to actin. FEBS Lett 425: 251-255

Baluska F, Salaj J, Mathur J, Braun M, Jasper F, Samaj J, Chua N-H, Barlow PW, Volkmann D (2000) Root hair formation: F-actin-dependent tip growth is initiated by local assembly of profilin-supported F-actin meshworks accumulated within expansin-enriched bulges. Dev Biol 227: 618-632

Baluska F, Cvrckova F, Kendrick-Jones J, Volkmann D (2001) Sink plasmodesmata as gateways for phloem unloading. Myosin VIII and calreticulin as molecular determinants of sink strength? Plant Physiol 126: $39-46$ 
Boronenkov IV, Loijens JC, Umeda M, Anderson RA (1998) Phosphoinositide signaling pathways in nuclei are associated with nuclear speckles containing pre-mRNA processing factors. Mol Biol Cell 9: 3547-3560

Braun M, Baluska F, von Witsch M, Menzel D (1999) Redistribution of actin, profilin and phosphatidylinositol-4,5-bisphosphate in growing and maturing root hairs. Planta 209: 435-443

Carlsson L, Nyström LE, Sundkvist I, Markey F, Lindberg U (1977) Actin polymerizability is influenced by profilin, a low molecular weight protein in non-muscle cells. J Mol Biol 115: 465-483

Christensen HEM, Ramachandran S, Tan C-T, Surana U, Dong C-H, Chua N-H (1996) Arabidopsis profilins are functionally similar to yeast profilins: identification of a vascular bundle-specific profilin and a pollen specific profilin. Plant J 10: 269-279

Drobak BK, Franklin-Tong VE, Staiger CJ (2004) The role of the actin cytoskeleton in plant cell signaling. New Phytol 163: 13-30

Fu Y, Gu Y, Zheng Z, Wasteneys G, Yang Z (2005) Arabidopsis interdigitating cell growth requires two antagonistic pathways with opposing action on cell morphogenesis. Cell 120: 687-700

Gross P, Julius C, Schmelzer E, Hahlbrock K (1993) Translocation of cytoplasm and nucleus to fungal penetration sites is associated with depolymerization of microtubules and defense gene activation in infected, cultured parsley cells. EMBO J 12: 1735-1744

Gu J, Stephenson CG, Iadarola MJ (1994) Recombinant proteins attached to a nickel-NTA column: use in affinity purification of antibodies. Bio Techniques 17: 257-262

Gu Y, Fu Y, Dowd P, Li S, Vernoud V, Gilroy S, Yang Z (2005) A Rho family GTPase controls actin dynamics and tip growth via two counteracting downstream pathways in pollen tubes. J Cell Biol 169: 127-138

Hall A (1998) Rho GTPases and the actin cytoskeleton. Science 279: 509-514

Holzinger A, Valenta R, Lütz-Meindl U (2000) Profilin is localized in the nucleus-associated microtubule and actin system and is evenly distributed in the cytoplasm of the green alga Micrasterias denticulata. Protoplasma 212: 197-205

Huang S, McDowell JM, Weise MJ, Meagher RB (1996) The Arabidopsis profilin gene family. Plant Physiol 111: 115-126

Kaiser DA, Vinson VK, Murphy DB, Pollard TD (1999) Profilin is predominantly associated with monomeric actin in Acanthamoeba. J Cell Sci 112: 3779-3790

Kandasamy MK, McKinney EC, Meagher RB (2002) Plant profilin isovariants are distinctly regulated in vegetative and reproductive tissues. Cell Motil Cytoskeleton 52: 22-32

Kombrink E, Hahlbrock K (1986) Responses of cultured parsley cells to elicitors from phytopathogenic fungi. Plant Physiol 81: 216-221

Kost B, Lemichez E, Spielhofer P, Hong Y, Tolias K, Carpenter C, Chua N-H (1999) Rac homologues and compartmentalized phosphatidylinositol 4,5-bisphosphate act in a common pathway to regulate polar pollen tube growth. J Cell Biol 145: 317-330

Martelli AM, Ctaldi A, Manzoli L, Billi AM, Rubbini S, Gilmour RS, Cocco L (1995) Inositides in nuclei of Friend cells: changes of phosphoinositide and diacylglycerol levels accompany cell differentiation. Cell Signalling 7: 53-56

Mathur J, Hülskamp M (2002) Microtubules and microfilaments in cell morphogenesis in higher plants. Curr Biol 12: R696-R676

Mittermann I, Swoboda I, Pierson ES, Eller N, Kraft D, Valenta R, Heberle-Bors E (1995) Molecular cloning and characterization of profilin isoforms from tobacco (Nicotiana tabacum): increased profilin expression during pollen maturation. Plant Mol Biol 27: 137-146

Molendijk AJ, Bischoff F, Rajendrakumar CSV, Friml J, Braun M, Gilroy S, Palme K (2001) Arabidopsis thaliana Rop GTPases are localized to tips of root hairs and control polar growth. EMBO J 20: 2779-2788

Naton B, Hahlbrock K, Schmelzer E (1996) Correlation of rapid cell death with metabolic changes in fungus-infected, cultured parsley cells. Plant Physiol 112: 433-444
Ono E, Wong HL, Kawasaki T, Hasegawa M, Kodama O, Shimamoto K (2001) Essential role of the small GTPase Rac in disease resistance of rice. Proc Natl Acad Sci USA 98: 759-746

Opalski KS, Schultheiss H, Kogel K-H, Hückelhoven R (2005) The receptor-like MLO protein and the RAC/ROP family G-protein RACB modulate actin reorganization in barley attacked by the biotrophic powdery mildew fungus Blumeria graminis f. sp. hordei. Plant J 41: 291-303

Osborne SL, Thomas CL, Gschmeissner S, Schiavo G (2001) Nuclear PtdIns(4,5)P2 assembles in a mitotically regulated particle involved in pre-mRNA splicing. J Cell Sci 114: 2501-2511

Ridley A (2001) Rho family proteins: coordinating cell responses. Trends Cell Biol 11: 471-477

Robatzek S, Somssich IE (2001) A new member of the Arabidopsis WRKY transcription factor family, AtWRKY6, is associated with both senescence- and defence-related processes. Plant J 28: 123-133

Schlüter K, Schleicher M, Jockusch BM (1998) Effects of single amino acid substitutions in the actin-binding site on the biological activity of bovine profilin I. J Cell Sci 111: 3261-3273

Schmelzer E (2002) Cell polarization, a crucial process in fungal defence. Trends Plant Sci 7: 411-415

Schultheiss H, Dechert C, Kogel K-H, Hückelhoven R (2003) Functional analysis of barley RAC/ROP G-protein family members in susceptibility to the powdery mildew fungus. Plant J 36: 589-601

Staiger CJ, Goodbody K, C Hussey PJ, Valenta R, Drobak BK, Lloyd CW (1993) The profilin multigene family of maize: differential expression of three isoforms. Plant J 4: 631-641

Staiger CJ, Yuang M, Valenta R, Shaw PJ, Warn RM, Lloyd CW (1994) Microinjected profilin affects cytoplasmic streaming in plant cells by rapidly depolymerizing actin microfilaments. Curr Biol 4: 215-219

Staiger CJ, Gibbon BC, Kovar DR, Zonia LE (1997) Profilin and actindepolymerizing factor: modulators of actin organization in plants. Trends Plant Sci 2: 275-281

Sun H-Q, Kwiatkowska K, Yin H (1995) Actin monomer binding proteins. Curr Opin Cell Biol 7: 102-110

Takemoto D, Jones DA, Hardham AR (2003) GFP-tagging of cell components reveals the dynamics of subcellular re-organization in response to infection of Arabidopsis by oomycetous pathogens. Plant J 33: 775-792

Tarachandani A, Wang Y (1996) Site-directed mutagenesis enabled preparation of a functional fluorescent analog of profilin: biochemical characterization and localization in living cells. Cell Motil Cytoskeleton 34: 313-323

Valenta R, Duchêne M, Pettenburger K, Sillaber C, Valent P, Bettelheim P, Breitenbach M, Rumpold H, Kraft D, Schreiner O (1991) Identification of profilin as a novel pollen allergen: $\operatorname{IgE}$ autoreactivity in sensitized individuals. Science 253: 557-560

Valster AH, Pierson ES, Valenta R, Hepler PK, Emons AMC (1997) Probing the plant actin cytoskeleton during cytokinesis and interphase by profilin microinjection. Plant Cell 9: 1815-1824

Valster AH, Hepler PK, Chernoff J (2000) Plant GTPases: the Rhos in bloom. Trends Cell Biol 10: 141-146

Valster AH, Vidali L, Hepler PK (2003) Nuclear localization of profilin during the cell cycle in Tradescantia virginiana stamen hair cells. Protoplasma 222: 85-95

Vernoud V, Horton AC, Yang Z, Nielsen E (2003) Analysis of the small GTPase gene superfamily of Arabidopsis. Plant Physiol 131: 1191-1208

Vidali L, Hepler PK (1997) Characterization and localization of profilin in pollen grains and tubes of Lilium longiflorum. Cell Mot Cytoskeleton 36: 323-338

Volkmann D, Baluska F (1999) Actin cytoskeleton in plants: from transport networks to signaling networks. Microsc Res Tech 47: 135-154

Wong HL, Sakamoto T, Kawasaki T, Umemura K, Shimamoto K (2004) Down-regulation of metallothionein, a reactive oxygen scavenger, by the small GTPase OsRac1 in rice. Plant Physiol 135: 1447-1456

Zheng Z-L, Yang Z (2000) The Rop GTPase: an emerging signaling switch in plants. Plant Mol Biol 44: 1-9 